(D)

CORPUS PUBLISHERS

\section{Current Research} in Emergency Medicine (CREM)

ISSN: 2832-5699

Volume 1, Issue 2, 2021

Article Information

Received date : 27 September, 2021

Published date: 05 October, 2021

\section{${ }^{*}$ Corresponding author}

Jacky Sia, Emergency Department,

Fraser Health Authority, Delta, BC,

Canada

\section{Key Words}

Emergency Department; Computerized Tomography; Ultra Sound; Trauma; Vaginal Bleeding

\section{DOI: 10.54026/CREM/1007}

Distributed under: Creative Commons CC-BY 4.0

\title{
Tip Appendicitis - Will This Case Report Change Our Practice?
}

Jacky Sia ${ }^{*}$

Emergency Department, Fraser Health Authority, Delta, BC, Canada

\section{Abstract}

A 24-year-old female visits an emergency department for a few hours' records of proper decrease quadrant pain. She had a proper ovarian cyst in 2017 that used to be dealt with conservatively. Pathology confirmed moderate focal irritation inside the appendicular wall and periappendicitis. The affected person was once discharged the subsequent day with an uneventful recovery.

\section{Case Summary}

A 24-year-old lady visits an emergency department for a few hours' history of right lower quadrant pain. She had a right ovarian cyst in 2017 that was treated conservatively. During her visit, she complained of gradual onset of right lower quadrant pain with mild tenderness. She had no fever, gastrointestinal upset, urinary symptoms, history of trauma, or vaginal bleeding. On arrival, her condition was stable. Blood pressure was $102 / 58 \mathrm{mmHg}$; pulse rate was 82 beats per minute; body temperature was $36^{\circ} \mathrm{C}$; and respiratory rate was 18 breaths per minute with oxygen saturation of $98 \%$ in room air. On examination, she had mild localized pain and tenderness over the right lower quadrant. Digital rectal and vaginal examinations were not performed. Rovsing's and psoas signs were negative. Her laboratory tests, including white blood cell count, C-reactive protein, and urinalysis, including for pregnancy, were normal. Abdominal and pelvic Ultra Sound (US) were normal except for local tenderness on the right lower quadrant. Subsequent Computerized Tomography (CT) of the abdomen raised suspicion of acute uncomplicated tip appendicitis (Figure 1\&2). She was subsequently transferred to the surgical unit for laparoscopic appendectomy. Pathology showed mild focal inflammation within the appendicular wall and periappendicitis. However, no neutrophils were observed within the appendicular lumen, and luminal fecalith was noted. The patient was discharged the next day with an uneventful recovery.
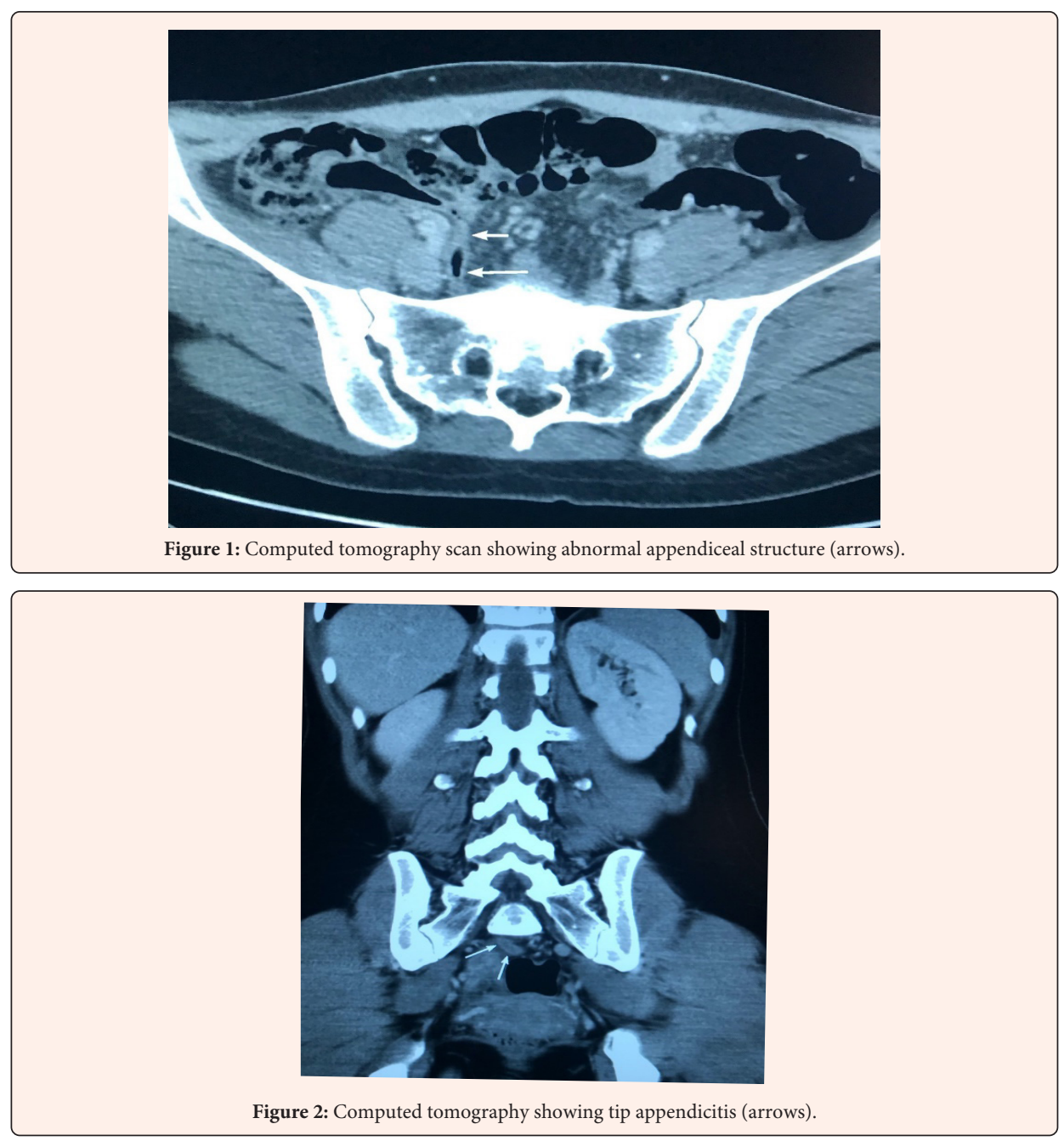


\section{Discussion}

General

Acute appendicitis has been one of the most common causes of abdominal surgeries since 1886, when Harvard's professor of pathological anatomy, Heber Fitz, first published his study on abdominal disorders. Professor Fitz pointed out that inflammation of the vermiform appendix was the most common cause of abdominal disorders in 466 cases unsuccessfully treated for various conditions. No wonder appendicitis remains one of the most significant diagnostic challenges in abdominal surgery: the symptoms sometimes mimic other conditions, they might be unspecific, and the diagnostic criteria are not reliable in cases of atypical presentations [1]. One of the atypical presentations is tip appendicitis, a condition in which the distal part of the appendix is inflamed, whereas the proximal portion shows no changes whatsoever. Although it might seem like a slight variation of the same condition, the implications are enormous, mainly when relying on imaging techniques to confirm or reject the diagnosis. In this case, abdominal and pelvic CT needed to be performed even though the patient was afebrile with normal blood tests and relatively benign US findings before a definitive diagnosis could be made.

\section{Clinical signs}

Various clinical signs have been described for diagnosing acute appendicitis (Table 1). In the present case, localized tenderness was the only positive clinical sign detected $[2,3]$.

Table 1: Different clinical signs and their respective probabilities for diagnosing acute appendicitis.

\begin{tabular}{|c|c|c|}
\hline Clinical Sign & Examination & Probability \\
\hline Local tenderness & Tenderness at McBurney point & Likelihood ratio 6.4 \\
\hline Rovsing sign & $\begin{array}{l}\text { right lower quadrant pain when left } \\
\text { lower quadrant is being pressed }\end{array}$ & Likelihood ratio 3.5 \\
\hline Obturator sign & $\begin{array}{l}\text { Right lower quadrant pain when } \\
\text { right hip is internally rotated }\end{array}$ & Likelihood ratio 3.5 \\
\hline Psoas sign & $\begin{array}{l}\text { complaints of pain over right lower } \\
\text { quadrant when patient extends his/ } \\
\text { her right hip. }\end{array}$ & Likelihood ratio 3.2 \\
\hline \multirow[b]{2}{*}{ Dunphy's sign } & \multirow{2}{*}{$\begin{array}{l}\text { right lower quadrant pain when } \\
\text { coughing }\end{array}$} & Sensitivity $78 \%$ \\
\hline & & Specificity $79 \%$ \\
\hline $\begin{array}{l}\text { Markle's test (heel- } \\
\text { drop test) }\end{array}$ & $\begin{array}{l}\text { Patient standing in tip-toe posture } \\
\text { and then landed with thump sound. } \\
\text { If pain at right lower quadrant, then } \\
\text { the test is positive }\end{array}$ & Sensitivity $74 \%$ \\
\hline
\end{tabular}

Clinical scoring system $[2,4]$

After the physical examination, a clinician would need to determine whether the patient has a high probability of acute appendicitis or not. Various clinical scoring systems have been described with different likelihood ratios (Table 2). In the present case, the Alvarado score was only two, which indicates that appendicitis was unlikely. Most likely, this patient would be discharged already in busier hospitals. However, none of these scoring systems have been used to validate tip appendicitis.

Table 2: Comparison of the different scoring systems.

\begin{tabular}{|c|c|c|c|}
\hline & ALVARADO & $\begin{array}{c}\text { Appendicitis } \\
\text { Inflammatory } \\
\text { Response Score }\end{array}$ & $\begin{array}{c}\text { Pediatric } \\
\text { Appendicitis } \\
\text { Score }\end{array}$ \\
\hline Population & Adult / & Adult / Pediatric & $\begin{array}{c}\text { Pediatric 3-18 } \\
\text { with abdominal } \\
\text { pain }<4 \text { days }\end{array}$ \\
\hline Nausea/ vomiting & 1 & 1 & 1 \\
\hline
\end{tabular}

\begin{tabular}{|c|c|c|c|}
\hline Anorexia & 1 & 1 & 1 \\
\hline Migration of pain & 1 & & 1 \\
\hline $\begin{array}{l}\text { Right lower } \\
\text { quadrant pain }\end{array}$ & & 1 & $\begin{array}{l}\text { 2(right lower } \\
\text { quadrant pain } \\
\text { when coughing } \\
\text { / percussion / } \\
\text { hopping) }\end{array}$ \\
\hline $\begin{array}{c}\text { Right lower } \\
\text { quadrant } \\
\text { tenderness }\end{array}$ & 2 & & 2 \\
\hline Rebound pain & 1 & $\begin{array}{l}\text { Light: } 1 \\
\text { Medium: } 2 \\
\text { Strong: } 3\end{array}$ & \\
\hline Fever & $1: \geq 37.3 \mathrm{C}$ & $1: \geq 38.5 \mathrm{C}$ & $1: \geq 38 \mathrm{C}$ \\
\hline $\begin{array}{c}\text { Leukocytosis } \geq \\
10,000 \text { per } \mu \mathrm{L} \\
(10.0 \times 109 \text { per } \mathrm{L})\end{array}$ & 2 & $\begin{array}{c}1 \\
2: \geq 15,000 \\
\text { per } \mu \mathrm{L}\end{array}$ & 1 \\
\hline $\mathrm{PMN} \geq 75 \%$ & 1 & $\begin{array}{c}1 \\
2: \geq 85 \%\end{array}$ & 1 \\
\hline CRP & & $\begin{array}{c}\text { 1: } 10 \text { to } 49 \mathrm{~g} \\
\text { per } \mathrm{L} \\
2: \geq 50 \text { g per } \mathrm{L}\end{array}$ & \\
\hline Maximum & 10 & 12 & 10 \\
\hline Not Likely & $0-3$ & $0-4$ & $0-3$ \\
\hline Moderate Likely & $4-6$ & $5-8$ & $4-6$ \\
\hline $\begin{array}{c}\text { Likely } \\
\text { Appendicitis }\end{array}$ & $\geq 7$ & $\geq 9$ & $\geq 7$ \\
\hline
\end{tabular}

Laboratory tests

Laboratory tests are neither sensitive nor specific for diagnosing acute appendicitis, not to mention tip appendicitis. Other supporting laboratory tests, such as lactoferrin an calprotectin, may be elevated in acute appendicitis. In the case of perforated appendicitis, bilirubin and fibrinogen level may be helpful. However, none of these tests have been validated in tip appendicitis.

\section{Diagnostic imaging}

Clinicians agree that the first-line imaging technique for diagnosing appendicitis should be ultrasound [5]. Over the past 30 years, various examination techniques and diagnostic criteria have been developed. Typically, doctors rely on the compression technique and appendix diameter measurements to arrive at a decision. However, visualizing the appendix US is not always possible. Tip appendicitis is rare. Statistics say only approximately $5 \%$ of pathologically confirmed cases involve the tip.1 Recently, Leung et al. [6] retrospectively reviewed all diagnostic US and CT imaging reports and found that tip appendicitis is proven and confirmed by CT if the US is suspicious. Among 55 patients with imaging proven to have tip appendicitis in their study, 21 patients were indicated for surgery because of their progressive clinical presentation and imaging findings. Only 9 out of the 21 were proven to have appendicitis. In other words, $46 / 55$ patients have radiological evidence of tip appendicitis but turned out to be false positive. Of note, Leung et al. f0und no correlation between fever and true appendicitis. Only right lower quadrant pain and nausea were positively correlated and observed in all of the nine patients. Not much research regarding the US and tip appendicitis have been conducted specifically in adults. The occurrence is rare. With appendicitis, a CT scan demonstrates obvious advantages in sensitivity (98.5\%), specificity (98\%), true positives $(99.5 \%)$, and true negatives (93.9\%) compared with US diagnostics [7]. 


\section{Appendicitis Score-Will This Change Our Practice?}

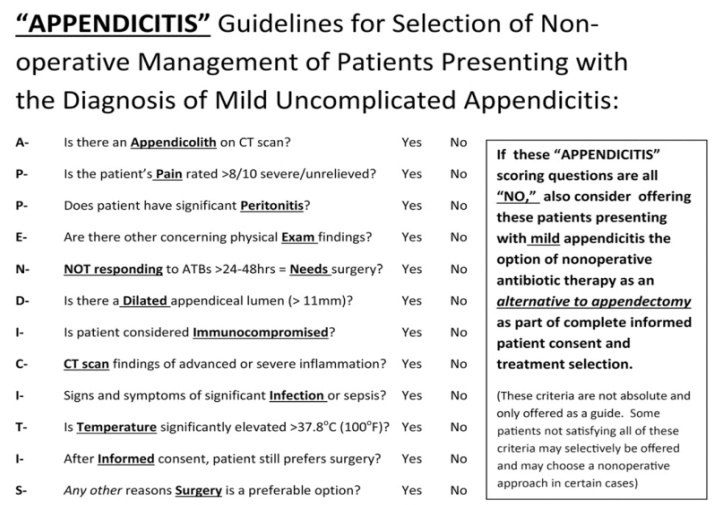

Figure 3: Guidelines for the selection of non-operative management of mild uncomplicated appendicitis.8 Reprinted with permission.

Management guidelines remain a controversial topic. In a paper published by Horattas et al., they suggested a comprehensive scoring system called APPENDICITIS (Figure 3) [8]. If a patient has mild appendicitis, they would have opted for intravenous antibiotics or surgery. For a non-allergic patient, outpatient antibiotic ampicillin/ sulbactam, $3.0 \mathrm{~g}$ intravenously every 6 hours, or a similar broad-spectrum antibiotic would be given. The endpoint would be adequate pain management and the normalization of leukocytosis. Subsequently, the patient would be switched to oral antibiotic amoxicillin/ clavulanic acid, $875 \mathrm{mg}$ every 12 hours for 7 to 10 days. In the case of penicillin allergies, intravenous ciprofloxacin and metronidazole would be used. Oral ciprofloxacin an metronidazole will be administered subsequently when the patient has no abdominal pain and the blood tests do not show any leukocytosis. In the Horattas et al. study, 36 patients were eligible for antibiotic therapy, and 14 of the 36 were offered intravenous treatment. One changed his mind, and elective appendectomy was performed. Thirteen patients made a complete recovery after antibiotics. Twelve patients had no recurrence within 3 years, and one patient had recurrence within 1 year [8]. Despite the small sample size, the results were quite interesting. If the APPENDICITIS scoring system could be validated in our medical system, patients with mild acute appendicitis, such as tip appendicitis, could be treated as an outpatient without emergency surgery. This could save a lot of material and human resources while ensuring patient safety. Broad nationwide research should be considered to collect further evidence on whether an intravenous antibiotic is applicable in mild appendicitis. In addition, due to the high negative appendectomy rate in pediatrics, surgeries could be delayed in this population until children show classical clinical features of acute appendicitis [6]. Based on the Cochrane database and metaanalysis, appendectomy is still the key to successful management in full-blown acute appendicitis [9]. Antibiotic treatment regimens only have a $60 \%$ successful rate in severe appendicitis, with high reattendance and admission rate for surgery. This conservative approach would only be considered in elderly patients with multiple comorbidities or refusal of surgical intervention.

\section{Conclusion}

Tip appendicitis is a rare entity occurrence and may not be adequately evaluated using any existing scoring system. Insufficient data or studies have been collected on tip appendicitis in an adult population. Currently, no consensus has been reached on how to stratify the severity of acute appendicitis. In this report, an APPENDICITIS scoring system was introduced for severity stratification. If intravenous antibiotics could be used in acute cholecystitis or acute diverticulitis, it could help treat mild appendicitis or tip appendicitis, as well. A pilot study across Canada may be conducted to validate this scoring system. Such a scoring system can change emergency physicians' and surgeons' practices and help avoid unnecessary emergency or even negative appendectomies while ensuring patient safety.

\section{Conflicts of Interest: None}

\section{Financial Support: None}

\section{References}

1. Mazeh H, Epelboym I, Reinherz J, Greenstein AJ, Divino CM (2009) Tip appendicitis: clinical implications and management. American Journal of Surgery 197(2): 211-215.

2. Wagner M, Tubre DJ, Asensio JA (2018) Evolution and current trends in the management of acute appendicitis. Surgical Clinics of North America 98(5): 10051023 .

3. Dunphy JE, Botsford TW (1953) Examination of the abdomen: Acute appendicitis. In: Physical Examination of the Surgical Patient, pp. 123-124.

4. De Castro SMM, Ünlü C, Steller EP, van Wagensveld BA, Vrouenraets BC (2012) Evaluation of the appendicitis inflammatory response score for patients with acute appendicitis. World Journal of Surgery 36(7): 1540-1545.

5. Mostbeck G, Adam EJ, Nielsen MB, Claudon M, Clevert D et al. (2016) How to diagnose acute appendicitis: ultrasound first. Insights into Imaging 7(2): 255-263.

6. Leung B, Madhuripan N, Bittner K, Rastegar V, Banever G, et al. (2019) Clinical outcomes following identification of tip appendicitis on ultrasonography and CT scan. Journal of Pediatric Surgery 54(1): 108-111.

7. Pickhardt PJ, Lawrence EM, Pooler BD, Bruce RJ (2011) Diagnostic performance of multidetector computed tomography for suspected acute appendicitis. Annals of Internal Medicine 154(12): 789-796.

8. Horattas MC, Horattas IK, Vasiliou EM (2018) Early uncomplicated appendicitiswho can we treat nonoperatively? The American Surgeon 84(2): 174-180.

9. Wilms IM, Hoog DE, Visser DC, Janzing HM (2011) Appendectomy versus antibiotic treatment for acute appendicitis. Cochrane Database of Systematic Reviews (11):CD008359. 